\title{
Creating a 3D Model of the Existing Historical Topographic Object Based on Low-Level Aerial Imagery
}

\author{
Maciej Smaczyński ${ }^{1}$ [D Tymoteusz Horbiński ${ }^{1}$ (D
}

Received: 4 September 2020 / Accepted: 21 October 2020 / Published online: 10 November 2020

(c) The Author(s) 2020

\begin{abstract}
The aim of the research was to create 3D cartographic visualization based on various sources and data types of an existing historical topographic object. The authors will present the stages of the research for the historical windmill located in Poland. The most recent surveying methods, such as GNSS method, low-level aerial photogrammetry and advanced IT tools, including computer software, will be applied for this purpose. The sequence of research procedures adopted by the authors of this article allowed for the creation of a 3D model of the tested windmill and its implementation into the Internet environment. This allowed to increase the cartographic range of spatial information. In addition, the research results allow for the extension of research in the field of history and can be the basis for their implementation.
\end{abstract}

Keywords Windmill $\cdot$ UAV $\cdot$ Creating 3D model $\cdot$ Multimedia visualization of spatial features $\cdot$ Cultural heritage

\section{Zusammenfassung}

Das Hauptziel dieser Forschung war die Erstellung einer kartographischen 3D-Visualisierung, basierend auf verschiedenen Quellen und Datentypen eines vorhandenen historischen topographischen, Objekts. Die Verfasser dieses Artikels stellen die Phasen der Forschung für eine in Polen gelegene historische Windmühle dar. Zu diesem Zweck werden die neuesten Vermessungsmethoden wie die GNSS-Methode, die Photogrammetrie aus den niedrigeren Flugflächen sowie die fortgeschrittenen IT-Tools, inklusive der Computersoftware, angewandt. Die von den Autoren gewählte Reihenfolge des Forschungsverfahrens ermöglichte die Erstellung eines 3D-Modells der untersuchten Windmühle und deren Implementierung in die Internetumgebung. Dieser Schritt trug zur Vergrößerung der kartographischen räumlichen Informationsreichweite bei. Die Forschungsergebnisse bieten darüber hinaus die Möglichkeit, die Forschung auf dem Gebiet der Geschichte zu erweitern und sie können eine Grundlage für deren Umsetzung sein.

Schlüsselwörter Windmühle $\cdot \mathrm{UAV} \cdot 3 \mathrm{D}-$ Modell erstellen $\cdot$ Multimediale Visualisierung der räumlichen Objekte $\cdot$ das Kulturerbe

\section{Introduction}

The landscape determinants of Wielkopolska region in preindustrial and early industrial times were, among others, windmills (Lorek and Medyńska-Gulij 2019). They had a great influence on the agro-industrial development of these areas. With the technological development in the production of flour, these facilities have lost their importance due

Maciej Smaczyński

maciej.smaczynski@amu.edu.pl

1 Department of Cartography and Geomatics, Adam Mickiewicz University, Poznan, Poland to displacement in favor of modern production plants, often located in larger urban agglomerations. It is worth noting that the remains of windmills still bear witness to the agro-industrial nature of this area, thus providing tangible evidence of the cultural heritage of Wielkopolska region. Bearing in mind that many objects of this type are deteriorating or have completely disappeared from the landscape of Wielkopolska region, the authors of this study would like to propose a compiled method of documenting an existing windmills. In addition, the authors point out an important aspect of the cartographic presentation of the obtained data and their further sharing to expand the group of recipients, which may contribute to the development of the already 
existing ones and carrying out new multidirectional scientific research in the field of cultural heritage.

The way of visualising data on maps is changing along with the technological advancement. Not such a long time ago topographic objects used to be demonstrated solely by means of symbols representing one style in graphics. A map user could only imagine how a specific object really looked, search for its pictures or embark on a journey. Fortunately for many people, the introduction of Street View to Google Maps was a breakthrough in terms of discovering such places (Leberl et al. 2009; Horbiński 2019). Since then, watching not only different places but also maps with 3D buildings, Augmented Reality or Virtual Reality views has become possible. Most of these opportunities concerned visualisation of the landscape elements present in the modern world. There are also cases in which the most recent technologies are used for visualising objects that are supposed to interblend with the present-day landscape in the future. Moreover, it is to be highlighted that field mapping and basic surveying, traditional for cartography, are not enough to produce as advanced visualisations as 3D models. In such case, it is necessary to employ the most recent technologies of spatial data collecting. To work out 3D models for larger areas, i.t. cities, LiDAR (Miřijovský and Langhammer 2015) and photogrammetry (Rossi et al. 2018) are commonly used. Both technologies allow one to generate point clouds on the basis of which 3D models are then created. Photogrammetric products obtained by unmanned aerial vehicles constitute the alternative to satellite and aerial views (Zhang and Kovacs 2012). At present, one may observe high demand for surveying relatively small areas of the earth's surface and the employment of a classic aerial or metric photogrammetric camera becomes uneconomical (Pérez et al. 2013), thus making the UAV technology an excellent alternative as a tool for obtaining low-level aerial imagery. In addition, unmanned aerial vehicles allow to register the Earth's surface from a new perspective, thanks to that it is possible to conduct innovative research in various fields and to make detailed measurements of the land surface (Smaczyński and Medyńska-Gulij 2017). One of them may be the observation of the dynamics of movement of participants of mass events and their analysis based on designed cartographic visualizations (Medyńska-Gulij et al. 2020). Furthermore, the most recent achievements in digital image processing and a dynamically developing sector of cameras (Remondino et al. 2016), by offering photogrammetric products with high definition and accuracy, encourage one to employ UAV technologies for collecting spatial data.

Creation of 3D cartographic visualization based on various sources and data types of an existing historical topographic object has become the main focus of this article. During the implementation of the main goal, the authors used low-level aerial imagery and archival topographic maps. An important aspect of research is the process of combining geohistorical and geocomputational approaches (Wilson 2005; Wästfelt 2020). Combining both approaches in research reduces the disadvantages and highlights the advantages of both approaches, that is why this article is based on combining what is old (archival maps, existing historical topographic object) and what is new (images from a low altitude, way of presenting results) (Horbiński and Lorek 2020).

The issues raised by the authors of this study have been described in the past by other researchers. The analyzed research presents a different approach and research goals from those adopted in this article. Perez-Martin et al. (2011) in their research attempted to systematize the methodology of graphic documentation of windmills in Spain. The authors of the study used hand-drawn sketches, photograms, photogrammetric studies obtained with the use of classic manned aircraft and data obtained through basic field measurements to develop a graphic presentation of the windmill. The proposed research methodology allowed for the development of an animated visualization of the examined object with the use of graphic computer software. Subsequent published studies concerned the considerations on the most appropriate methods of graphic and metric documentation of agroindustrial objects (Arias et al. 2006). In their study, the authors describe the short-range photogrammetry method based on photos obtained from the ground level with a digital camera. Moreover, Medyńska-Gulij and Żuchowski (2018) in their research attempted to design 3D maps based on archival 2D topographic maps, taking into account only the terrain surface. This article attempts to develop the previously described research in the preparation of documentation and the actual 3D cartographic presentation of the tested windmill.

The research methodology described in this article will be presented on the example of a windmill selected for the historical research. The authors assumed that the methodology strongly depends on the geometrical properties of the tested object. Hence, in this study it was assumed that the methodology would be considered in the aspect of a freestanding historical topographic object with relatively small dimensions. Moreover, the authors of the research specified two particular goals. The first one was to generate a 3D model of a windmill on the basis of images obtained by unmanned aerial vehicles and compilation with 3D model terrain obtained on the basis of an archival topographic map. The combination of these two 3D models will highlight the cartographic nature of the activities during the documentation of the windmills. Thanks to the 3D cartographic visualization created in this way, the user can experience the impression that accompanied the cartographer when creating the former topographic map of the examined object. The proposed solution increases the level of interactivity of the 
shared data, which also directly influences the greater possibilities of exploring and discovering the information contained therein (Kraak and Ormeling 2010). 3D maps in relation to 2D maps are characterized by a faster orientation of the user (viewer) in the field because real-world objects can be presented in a more realistic way (Nurminen et al. 2008). Therefore, the authors of this study decided to use low altitude imagery to create a 3D model of the research object. This selection ensures the acquisition of photographic documentation of the object and the construction of an accurate 3D model thanks to dedicated software, which additionally enables registration of its actual geometry and size, enabling remote measurements This type of data is extremely valuable for cultural heritage researchers and national services for the protection of monuments. The second goal was to implement the model created in the Internet environment. Currently, many methods are offered to present 3D cartographic visualizations. One of them is virtual reality (VR) (Halik 2018). The challenge during reconstruction work in VR is to keep the amount of data small, but ensuring a sufficient level of texture detail (Cöltekin et al. 2019). Unfortunately, the equipment needed to use such a method limits the audience. This problem is partially solved by the presentation of 3D cartographic visualizations in the augmented reality (AR) system. Due to the fact that this method uses a smartphone with a dedicated application, it allows you to increase the audience. However, the AR technology has shortcomings related mainly to the size of the files implemented into the application (Virtanen and Oulasvirta 2015). The traditional presentation of 3D cartographic visualizations on the Internet (Horbiński and Medyńska-Gulij 2017) counteracts the problems with the size of files. It eliminates hardware imperfections on the recipient's side, viewing is possible on many devices, such as a computer, laptop, tablet, smartphone, and offers the largest group of recipients, which is why the authors of this article decided to use this form of presentation of the obtained research results during the implementation of the second specific objective. Creating a geovisualisation of an existing historical topographic object entails a sequence of activities. The complexity of the conducted study required us to devise a specially designed workflow of the research process, illustrating the various research stages and file extensions of individual work results (Fig. 1). The individual components of the workflow will be described in more detail in later parts of the paper.

\section{Study Area}

The study was conducted in the western part of Poland, in the Greater Poland Voivodeship: in the Kamionka village. The research area selected, with a windmill in the centre, was of approximately 0.55 ha (Fig. 2). The choice of this

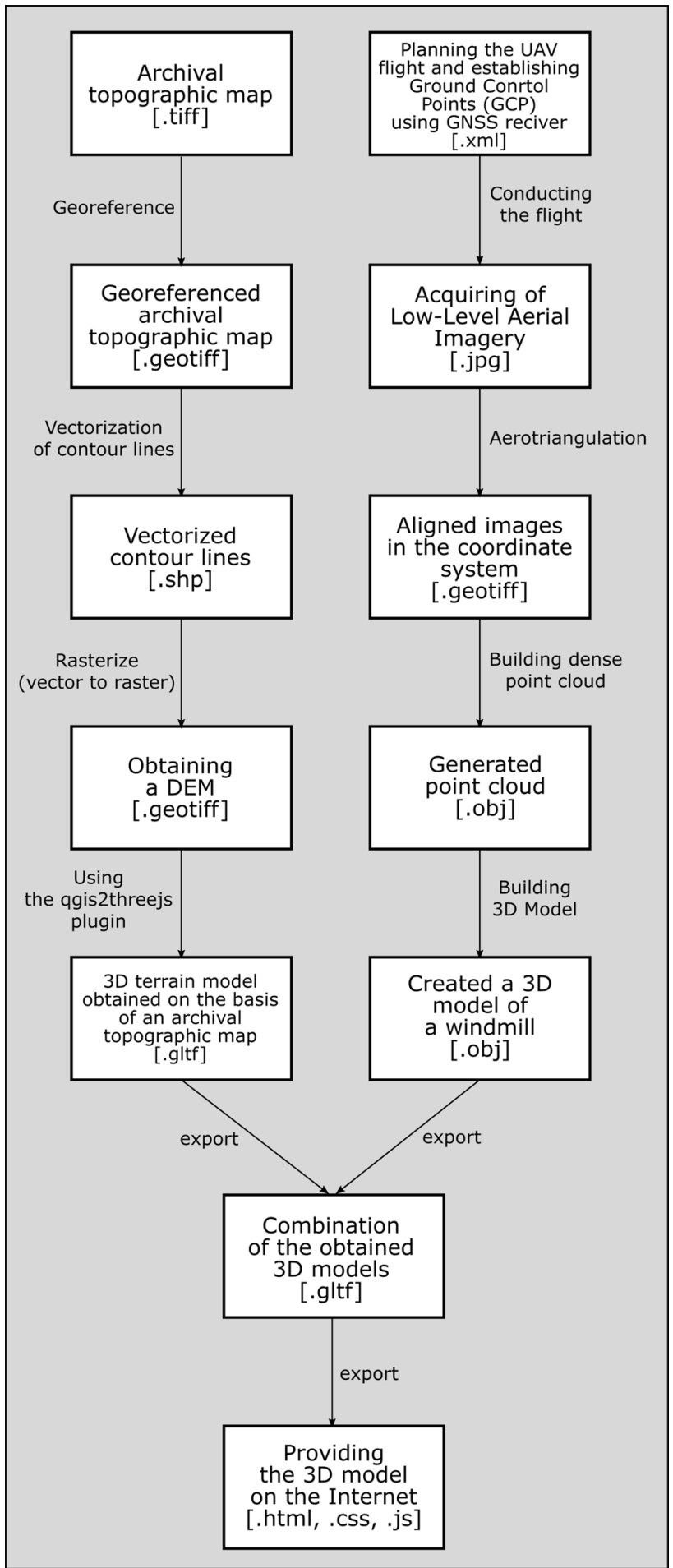

Fig. 1 Designed workflow of the research process

research area was dictated by the assumptions given in the introduction regarding the characteristics of the considered object, i.e. a free-standing historical topographic object with relatively small dimensions. Currently, the area neighbours upon a farm, a square with a playground and a junction of 


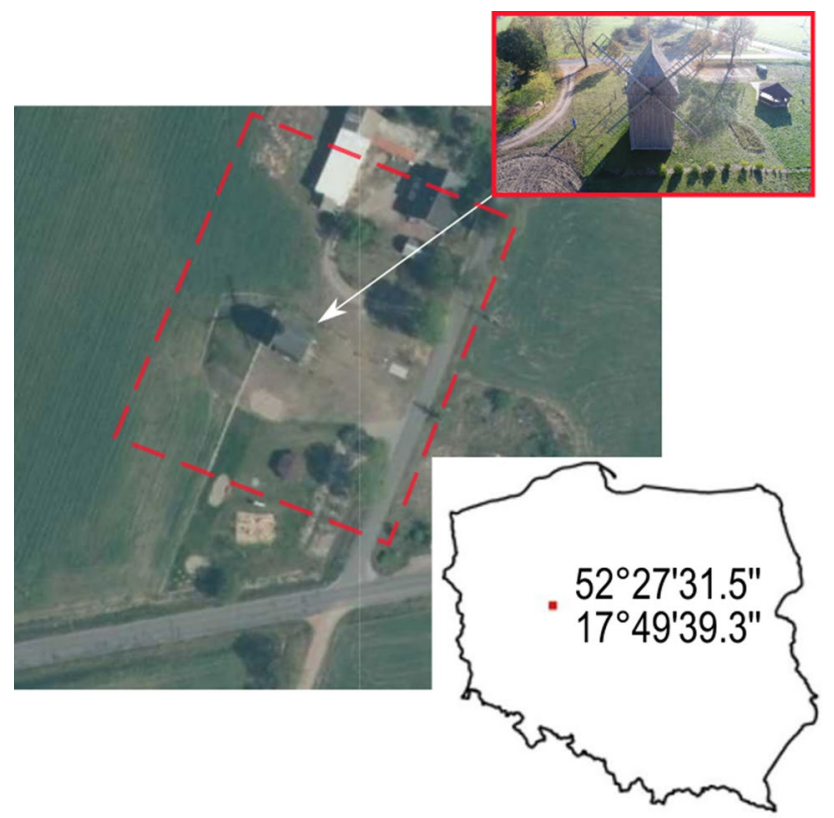

Fig. 2 Location of the studied area (background layer orthophotomap from national geoportal www.geoportal.gov.pl; coordinates of the studied area-WGS 84)

communal roads. Furthermore, the area is surrounded by arable land.

Messtischblätter from 1893, made at the scale of $1: 100,000$, is the oldest cartographic source confirming the existence of a windmill in the village of Kamionka that the authors could find. To prove this fact, Fig. 3 also depicts a part of Ürmesstischblätter from 1830 confirming that the windmill was created or moved in 1830-1893. Other historical publications also failed to provide a specific date. The windmill, gradually dilapidating over the years, was bought by the local authorities of the Witkowo commune, renovated and reopened for visitors in 2014.

Due to its large scale and lack of contour lines presenting relief, Messtischblätter from 1893 will not be used in further stages of the creation of the online 3D model, with a fragment of Messtischblätter from 1911 at the scale of 1:25,000 being used instead.

\section{Data Acquisition}

\subsection{Equipment and Software}

The authors of the research decided to create a virtual 3D model on the basis of low-level aerial imagery. The crucial task was to create a cartometric 3D model that would reflect the geometry and actual size of the object studied and could thus be used for all the necessary surveys. The unmanned aerial vehicle DJI Phantom Advanced +, equipped with the camera with 1" CMOS matrix and the $20 \mathrm{Mpx}$ lens. The platform used is equipped with Global Navigation Satellite Systems (GNSS), however, it is used only to secure the correct flight of the platform, which means that the platform fails to use corrections collected from reference stations to determine the position more accurately or save precise coordinates for particular images. Moreover, the authors assumed that the model would be defined in the selected coordinate system so that it would be then possible to integrate it with other cartographic analyses. Such assumptions determined the necessity to carry out aerotriangulation of the images obtained on the basis of ground control points (Nex and Remondino 2014). The GNSS Trimble R4 model 3 of the receiver was used for surveying. The images were then converted to the 3D form in the dedicated Agisoft Metashape Professional software.

\subsection{Preparatory Stage}

The first activity was to plan the flight path. In the research, it was conducted on the basis of orthophotomap obtained from a national geoportal (Fig. 1). The aim of preparing the flight path was to determine the procedure of obtaining images and locations of ground control points. Digital photogrammetry is a technique that by the use of algorithms
Fig. 3 Archival topographic maps presenting the historical object analysed

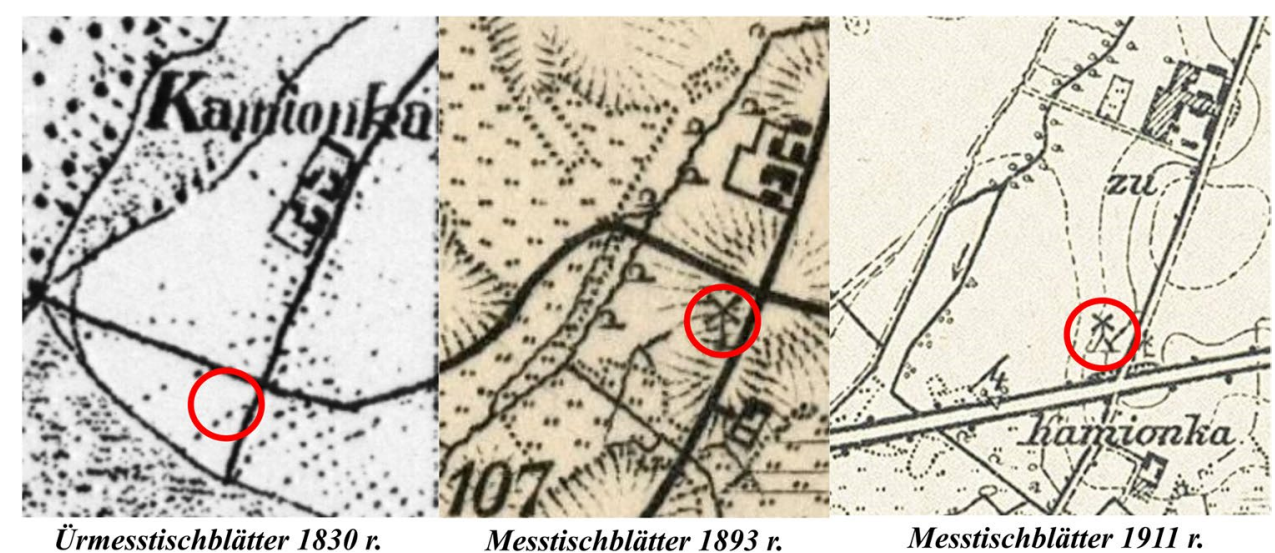

Messtischblätter 1893 r.
Messtischblätter $1911 r$. 
allows one to reconstruct land's topography as a 3D model providing spatial information from visible elements on two or more images obtained from different perspectives (Westoby 2012). On the basis of the images obtained it is possible to receive point clouds of a very high definition along with Digital Terrain Model (DTM), orthophotomaps and accurate 3D models of the land's surface (Colomina and Molina 2014; Clapuyt et al. 2017). The process of creating photogrammetric visualisations is usually conducted with the use of software with the Structure-from-Motion (SfM) algorithm that can calculate a 3D model on the basis of the sequence of overlapping images that record the modelled object from different perspectives (Westoby 2012). To be able to use the SfM algorithm in calculations, the authors of the research decided to obtain the images in such a way as to record the modelled object from all sides. Moreover, as Rossi et al. (2018) point out, taking into consideration the time necessary to prepare the model and its low costs, compared to classic photogrammetric techniques, the SfM model can be repeated on a regular basis and thus effectively used for monitoring and studying changes that occur on the particular area in a given time. The choice of 3D modelling with the use of the SfM algorithm, along with the designed flight path, imposed the necessity to obtain oblique images. The use of oblique images obtained using UAV technology is particularly effective for registering cultural heritage objects, due to the possibility of reproducing their details during 3D modeling (Aicardi et al. 2016a, b).

During the preparation process, except for the suitable planning of the flight path, it is of great importance to plan the network of ground control points carefully (Eugster and Nebiker 2008; Wang et al. 2008; Barazzetti et al. 2010; Anai et al. 2012; Nex and Remondino 2014). According to Gonçalves and Henriques (2015), the GNSS receiver and the IMU system installed on the UAV's platform are used mainly for navigation, stabilising the platform's flight or the external orientation of the images obtained. Furthermore, Gonçalves and Henriques (Gonçalves and Henriques 2015) indicate that for photogrammetric use it is best to employ the GCP network. The process of aerotriangulation, based on GCPs assumed, is time-consuming but allows one to adjust the imagery to the particular coordinate system (Aicardi et al. 2016a, b; Gerke and Przybilla 2016; Padró et al. 2019). Salvini and others (2015) indicate that surveying GCPs is possible through tacheometric surveying, which provides the best angular and linear accuracy between GCPs. Real-Time Kinematic (RTK) measurements ensure obtaining satisfactory measurement results, hence they are often used to measure photogrammetric control points (Clapuyt et al. 2016; de Kock and Gallacher 2016). It should be emphasized, that measurements of the GCPs with the use of RTK technology are possible only when we have access to differential corrections. It is mainly related to the area of measurements.
They differ in terms of access to the network of permanent reference stations and with access to the cellular network, through which corrections are sent with appropriate protocols. When access to differential corrections is impossible, it becomes necessary to perform classic tacheometric measurements. It should also be noted that while it is possible to perform satellite measurements, currently the measurement of the GCPs is possible through hybrid measurements using two techniques: tacheometric and satellite. Such a solution allows to obtain overtime observations, increasing the certainty of the measurement. Having considered the necessity to obtain oblique images to record the windmill from each angle as accurately as possible, it was established that the points should be located around the object, which would secure visibility of GCPs on all the images obtained. This approach resulted in establishing four GCPs on the opposite sides of the windmill along its diagonals, which allowed one to receive a particular "frame" in the centre of which the windmill was situated. The location of GCPs in the research area was demonstrated by white points in Fig. 4 (1-4 points).

Surveying each point included 30 periods with the recording interval of $1 \mathrm{~s}$ and surface corrections from the nearest reference station, located by the vector of $23 \mathrm{~km}$ from the research area, were used during the process. Table 1 presents the levelled coordinates of GCPs. The coordinates of GCPs, obtained through RTK, were defined in the rectangular PL-2000 coordinate system (zone 6) that was effective in Poland at the time.

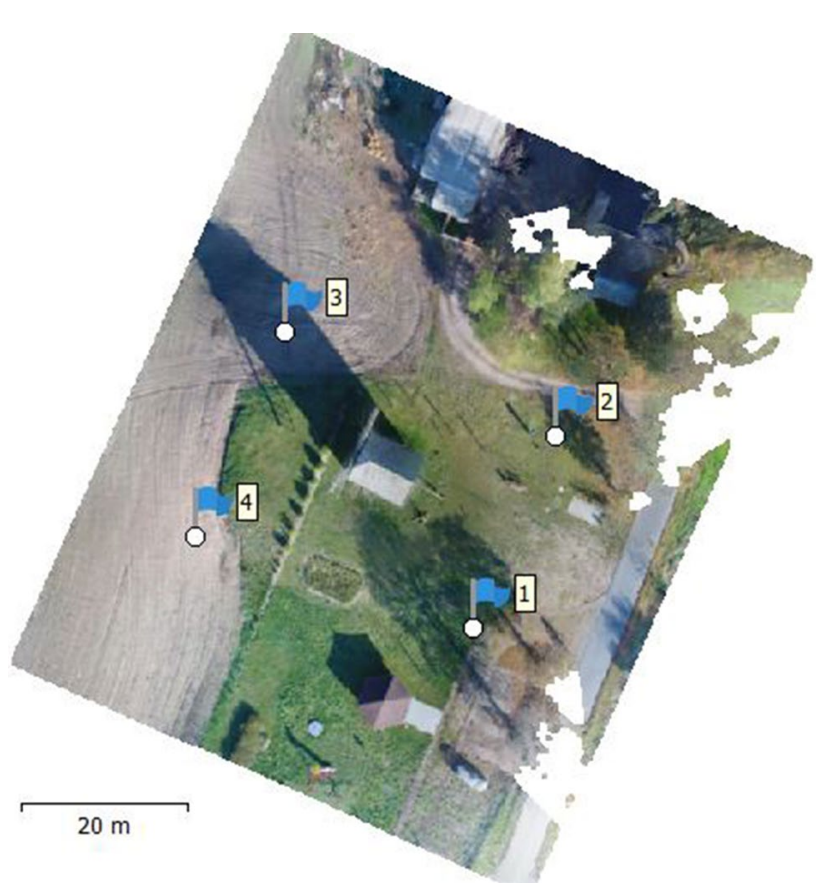

Fig. 4 The location of ground control points (white dots) in the studied area 
Table 1 List of ground control points [m]

\begin{tabular}{llll}
\hline $\mathrm{Nr}$ & $X$ & $Y$ & $H$ \\
\hline 11 & 5813936.289 & 6488292.644 & 109.703 \\
12 & 5813959.063 & 6488302.428 & 110.616 \\
13 & 5813971.428 & 6488270.257 & 109.894 \\
14 & 5813947.212 & 6488259.420 & 109.163 \\
\hline
\end{tabular}

\subsection{Conducting the Flight}

Weather conditions during the flight path were favourable. There was no rain, the wind speed was app. $4 \mathrm{~m} / \mathrm{s}$ and the sky was clear. The flight took place at the average altitude of $35 \mathrm{~m}$ AGL, along the flight path on different ceilings and lasted app. $20 \mathrm{~min}$. As a result of the flight path, 51 images of the $5472 \times 3078$ definition recording the windmill from all sides were obtained (Fig. 5).

\subsection{Aerotriangulation}

Aerotriangulation, whose aim was to define the images obtained in the selected coordinate system, was another stage of the research. The first step was to reconstruct their mutual internal orientation (Siebert and Teizer 2014). In the research, the images were adjusted to the same coordinate system in which GCPs were defined. Reconstructing mutual internal orientation is possible thanks to EXIF files of the images obtained that include metadata describing the images. It allows one to determine their approximate location in space. Then, the mutual orientation of images was reconstructed again, however, this time on the basis of GCPs assumed that had been previously surveyed by means of GNSS. The Agisoft Metashape Professional software was used for this purpose. According to Uysal et al. (2015), the software mentioned is used particularly frequently for working out images obtained from UAVs and allows one to generate Digital Terrain Model and orthophotomaps in the coordinate system defined by the user. As a result of aerotriangulation based on GCPs, the value of RMSE, describing deviations between tie points and the points calculated from the photogrammetric model generated, was calculated. On the basis of the results from Table 2, one can conclude that point no 2 had the largest error $(1.5 \mathrm{~cm})$, and the smallest error was determined for point no $4(0.8 \mathrm{~cm})$. The average value of RMSE calculated for all GCPs was $1.2 \mathrm{~cm}$.

\subsection{Creating a 3D Model}

The next stage of creating a 3D model of the windmill studied was to generate 3D point clouds based on low-level aerial imagery. In the research, the original size of the imagery obtained (i.e., $5472 \times 3078$ pixels) was used for the purpose, which allowed to get $1 \mathrm{~cm}$ of ground sampling distance (GSD). The point cloud hereby obtained consisted of $17,084,208$ points and its density was $2310 \mathrm{point} / \mathrm{m}^{2}$. Then,

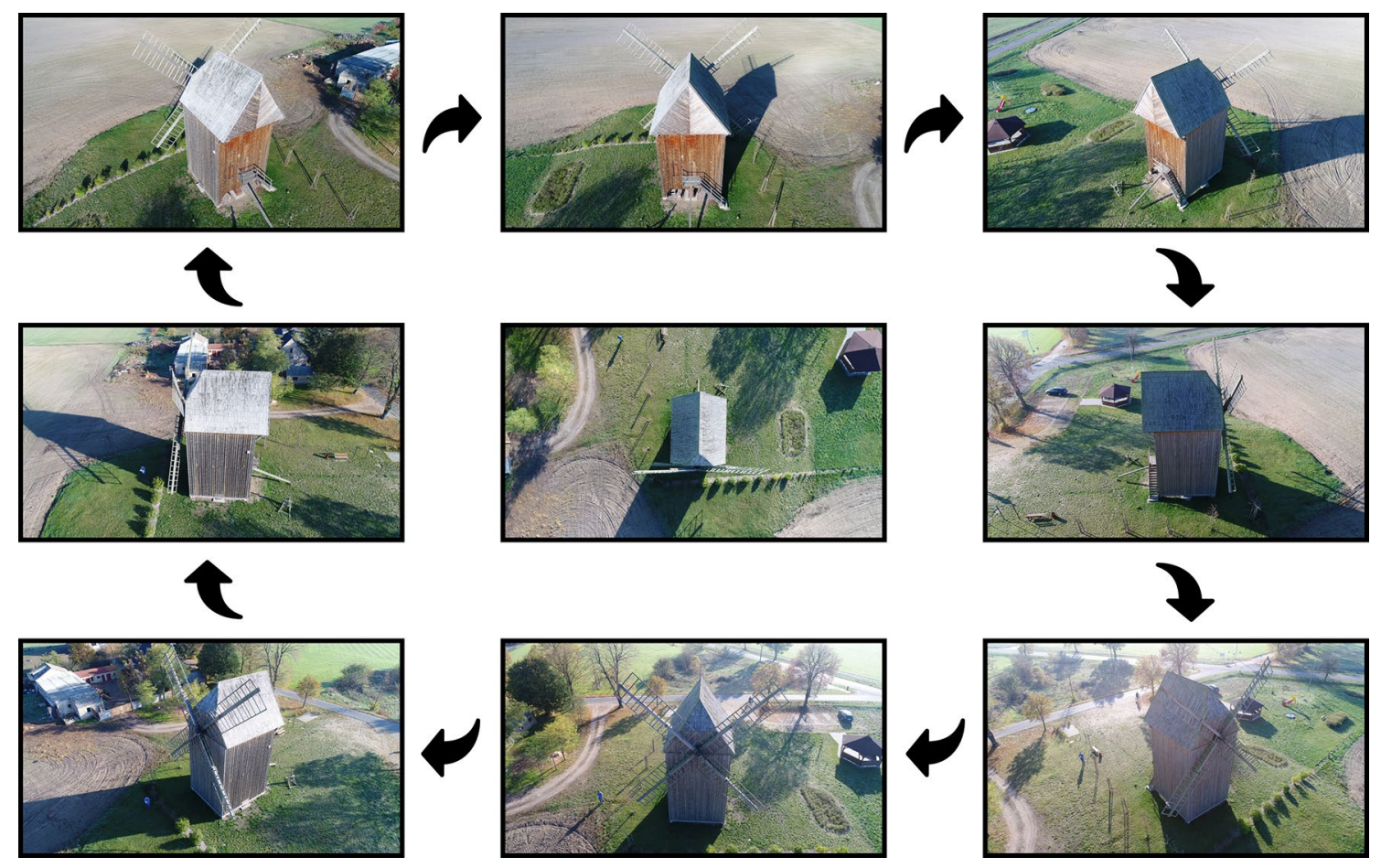

Fig. 5 Location of acquired images for further analysis 
Table 2 The calculated aerotriangulating errors of the GCPs

\begin{tabular}{lrrrll}
\hline Label & $X$ error $(\mathrm{m})$ & $Y$ error $(\mathrm{m})$ & $Z$ error $(\mathrm{m})$ & Total $(\mathrm{m})$ & Image (pix) \\
\hline 1 & -0.011 & -0.006 & -0.007 & 0.014 & 0.227 \\
2 & 0.001 & 0.013 & 0.007 & 0.015 & 0.150 \\
3 & 0.009 & -0.001 & -0.006 & 0.011 & 0.086 \\
4 & 0.000 & -0.006 & 0.006 & 0.008 & 0.077 \\
Total & 0.007 & 0.008 & 0.007 & 0.012 & 0.144 \\
\hline
\end{tabular}

using the point cloud, the 3D model of the land's surface, consisting of $1,138,925$ planes connected by 576,902 vertices, was generated. Figure 6 demonstrates the model with the texture applied.

The 3D model, calculated in Agisoft Metashape Professional, was exported to OBJ format in the WGS 84 (EPSG:4326) coordinate system.

\subsection{D Model of Archival Map}

Next, the 3D model of the archival map was created. The terrain included a small area around the windmill in the village of Kamionka. To create the model, the authors used a part of Messtischblätter from 1911 at the scale of 1:25,000. The map included a contour line drawing of the 1.25 interval (Lorek et al. 2018; Lorek and Medyńska-Gulij 2019; Cybulski et al. 2020). Each contour line was vectorised as a polygon (Fig. 7a) in QGis 3.12 (tracing) and assigned height in tabular data (Horbiński and Medyńska-Gulij 2017).

The vectors obtained were used for generating a digital elevation model (DEM). The authors employed the Rasterize (Vector to Raster) tool (Fig. 7b).

Then, the authors moved on to creating the 3D model, using the qgis2threejs plugin to QGIS 3.12. The plugin allows one to create a 3D model for the map in Raster or Vector format (Horbiński and Medyńska-Gulij 2017). It also makes it possible to insert other 3D elements (e.g., simple solid figures), however, for model files there are still problems with loading and, particularly, exporting the finished project. Therefore, the authors decided to create the 3D model of the archival map in qgis2threejs without inserting the previously created 3D model of the existing historical topographic object, namely the windmill. During the creation of the 3D model of the archival map the authors used the generated DEM onto which the archival map was applied. Resampling level was set at the value of 1 (Grid Size: $138 \times 73$ px, Grid Spacing: $0.00016 \times 0.00016$ px) to tone down the transition between particular heights assigned during vectorisation. Hence, the 3D model presented in Fig. 7c, which was then exported to the gITF format and will be used in the next stages, was produced.

\section{Virtual 3D Model}

The next step of data processing and creating the virtual 3D model was to connect the two elements created in previous stages, i.e., the 3D windmill model and 3D terrain model obtained on the basis of the archival topographic map. As the authors stated in the introduction, the combination of these two 3D models will emphasize the cartographic nature of activities during the documentation of windmills. Thanks to the 3D cartographic visualization created in this way, the user can experience the impression that accompanied the cartographer while creating the old map. The proposed solution increases the level of interactivity of the shared data, which also directly affects the greater possibilities of exploring and discovering the information contained therein (Kraak and Ormeling, 2010).

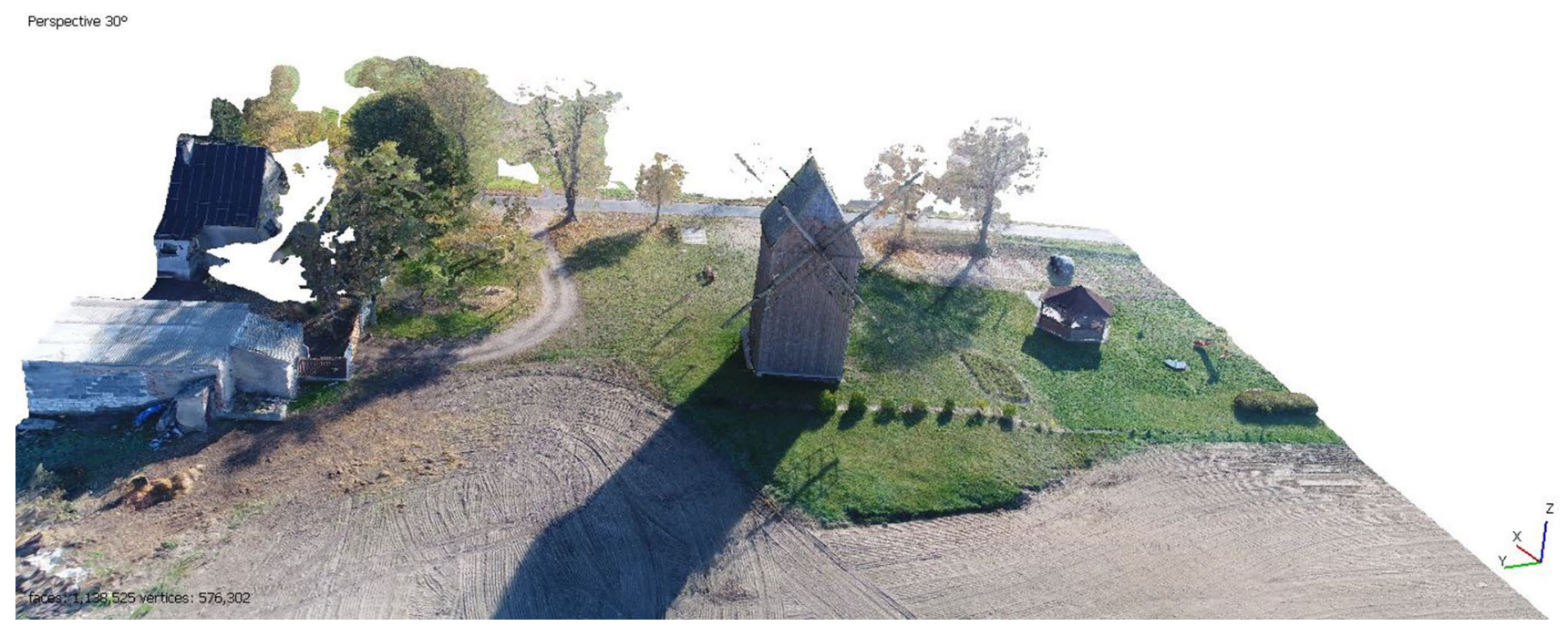

Fig. 6 The generated terrain model with the applied texture 
Fig. 7 a Vectorised contour lines for the area analysed; $\mathbf{b}$ digital elevation model of the area analysed; c 3D model, a fragment of the archival map; d virtual 3D model obtained thanks to the Three.js library
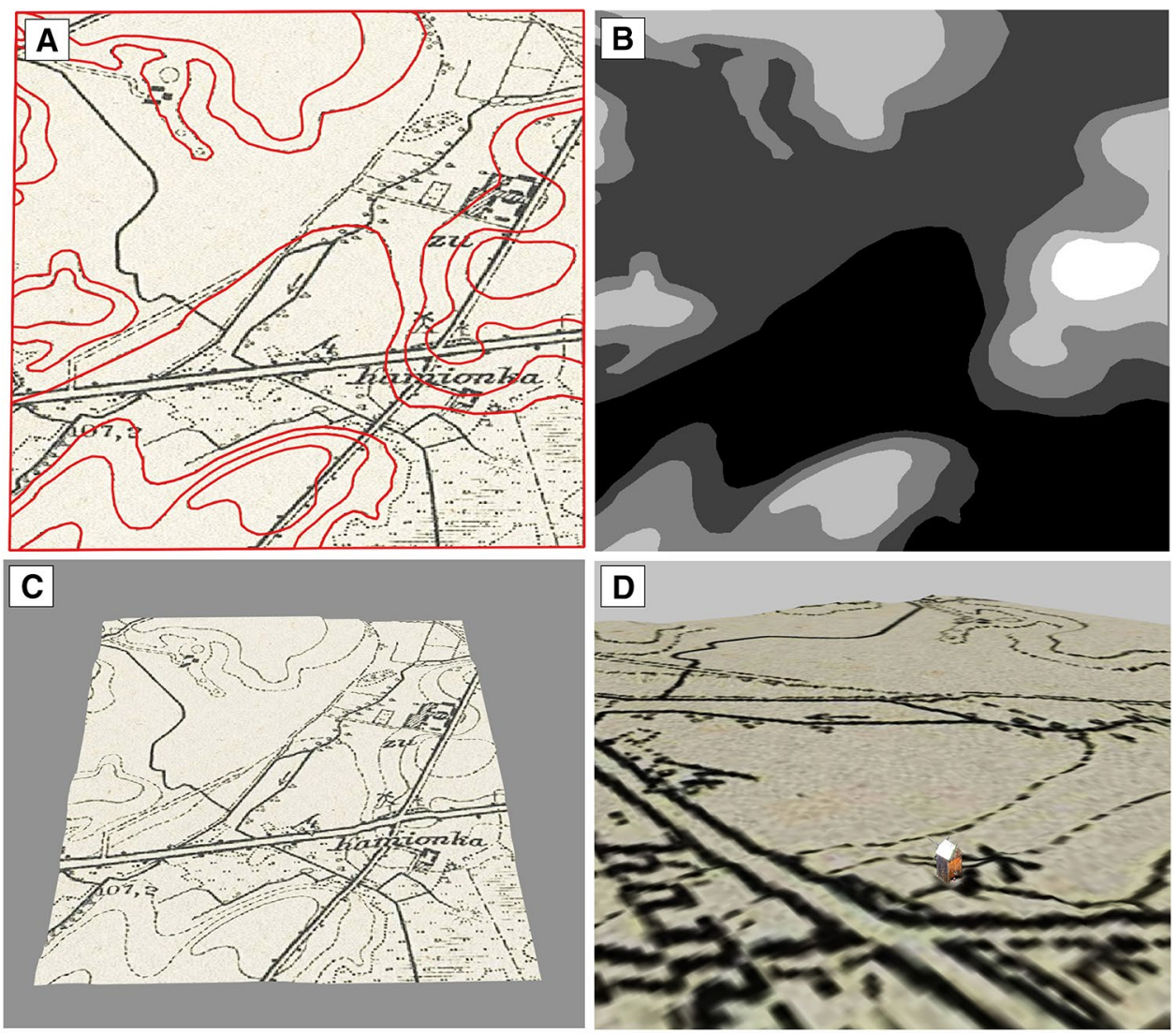

Connecting was carried out in Blender 2.82 and exported to the glTF format. Thus, the 3D model of the windmill placed on the archival topographic map was implemented to the code, using the JavaScript software and the Three.js library (and two extra plugins, GLTFLoader.js and OrbitControls.js). This is how the fully interactive 3D model, ready for being posted on the Internet (Fig. 7d-the last stage of the workflow), was created. The authors are aware of the limitations that result from the use of the Three.js library and the file extension.glTF, among others, loading files as a whole or limited loading on mobile devices. Nevertheless, the use of the Three.js library is visible primarily in research whose important element of work is the presentation of results (Stanton et al. 2017; Benesha et al. 2020). Providing 3D cartographic visualization on the Internet increases the audience and may result in the improvement of cultural awareness of the inhabitants of this region and more. Figure 8 shows the tested windmill before renovation (Fig. 8a), after renovation (Fig. 8b) and the view in the application (Fig. 8c).

\section{Conclusion and Future Work}

Obtaining low-level aerial images of the existing historical object, namely the windmill, allows one to prepare its detailed photographic documentation. However, aerotriangulation of the imagery, obtained on the basis of GCPs surveyed with the use of GNSS RTK and the SfM algorithm (Westoby 2012), makes it possible to generate a detailed 3D model of the object recorded and the surrounding relief with the accuracy up to several millimetres (Tab. 2). Currently, it is possible mostly due to specialist computer software, thanks to which visual data, obtained by UAVs, can be converted to digital form. Furthermore, according to Halik and Smaczyński (2018), the process of aerotriangulation and the lowered RMSE value may be additionally controlled on the basis of independent GCPs that do not participate in the aerotriangulation process, allowing one to estimate the probability of the result with the credibility of $68 \%$. The point cloud calculated in the research included $17,084,208$ points, resulting in the density of points at the level of 2310 points per each $\mathrm{m} 2$. The cloud was the basis for the 3D model of the historical windmill (Fig. 6), thus achieving the first particular goal. Creating a similar 3D model of the windmill along with its direct surroundings by the employment of classic land surveying techniques would be highly difficult and, above all, time-consuming. The results achieved in the research confirm high potential and usefulness of the UAV technology in work connected with modelling relief.

The 3D windmill model combined with the archival map allowed the authors to move on to programming. Using 
Fig. 8 a Windmill before renovation-july 2012 (Source: Google Maps); b Windmill after renovation-october 2020; c windmill view in the application
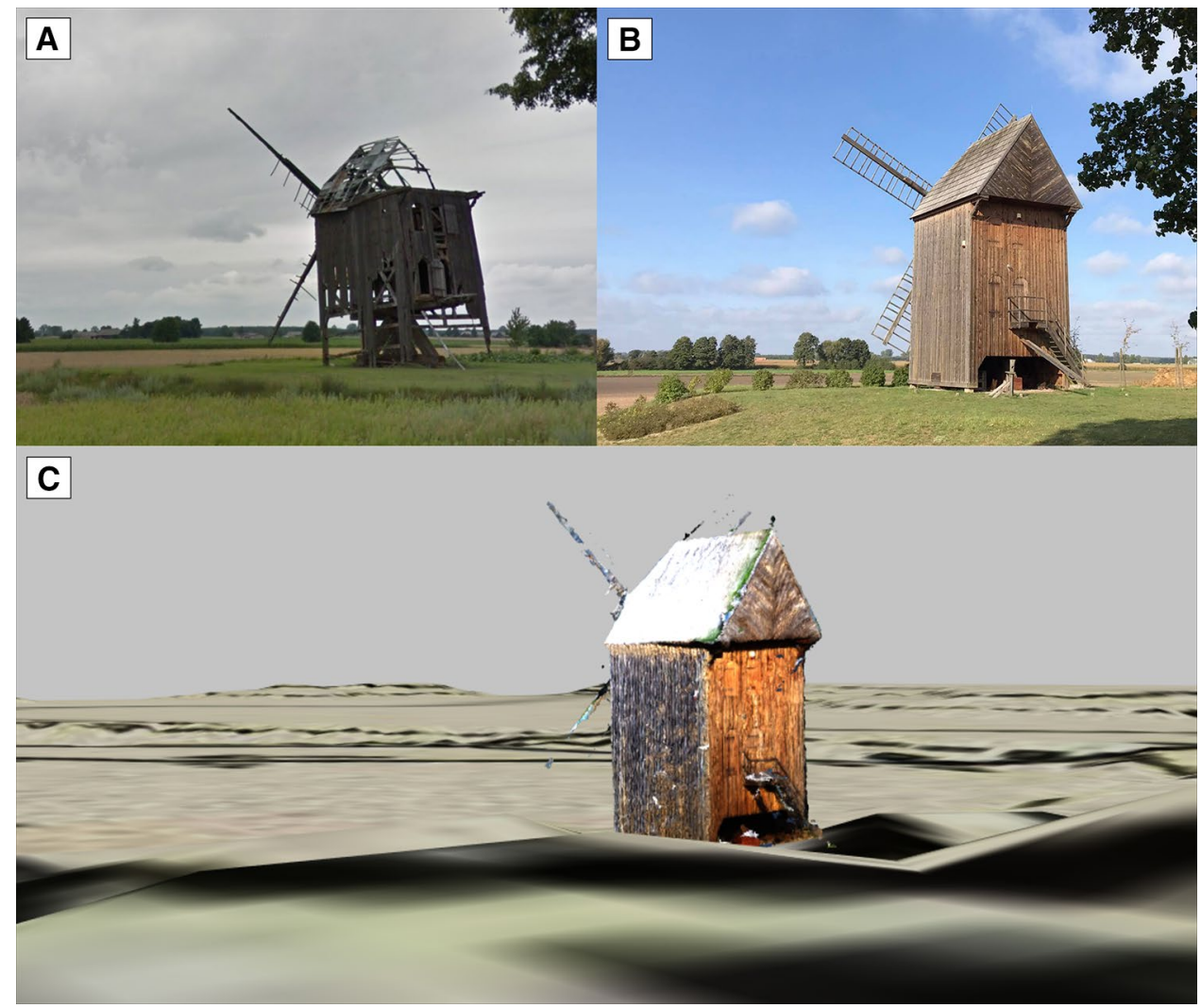

the Three.js library (and two plugins, GLTFLoader.js and OrbitControls.js), the implemented the target 3D model on the Internet (Fig. 7d), thus achieving the second particular goal. The hereby created Internet 3D windmill model placed on the archival map is entirely interactive. The OrbitControls.js plugin allows anyone to view the model from each perspective.

Having met the two particular goals adopted for the research, the authors can conclude that also the main aim of the research. In a comprehensive manner, it was primarily possible to combine archival data obtained from topographic maps (Fig. 7c) with a 3D model of the windmill obtained on the basis of low-level aerial imagery (Fig. 6). This confirms the correctness of the research conducted by the authors by combining geohistorical and geocomputational approches (Wilson 2005; Wästfelt 2020). Research conducted by the authors allows to increase the degree of interactivity in the way spatial data is presented (MacEachren 1994), and also by placing this data on the Internet, where the potential reach of geovisual recipients is increased. At this point, it should also be pointed out that the technical infrastructure, which, in accordance with the assumptions of the INSPIRE Directive, is becoming more and more dynamically developing in Poland and throughout Europe, is to provide access to spatial data (Bielecka and Medyńska-Gulij 2015). The authors of this article indicate that in the future, thanks to this technical infrastructure, the studies implemented on the Internet, i.e., three-dimensional cartographic visualizations will be made available to a wider group of users, including researchers. Undoubtedly, such a situation would contribute to the faster development of various fields of science and economy.

However, the authors of this article wish to suggest some issues that are worth examining and expanding on in future studies. The first one would be to finish the windmill model, i.e. perfect its level of detail. One needs to mention here all the works aimed at improving the point cloud that represents the historical object recorded. This issue is strictly connected with the camera used for obtaining low-level aerial images. Moreover, the authors indicate extending research aimed at increasing interactivity of the virtual 3D model of the historical object, through additionally programmed events-additional information about the facility. Following in the footsteps of Edler et al. (2019a, b), the authors also consider extending their research with audio-visual elements that enable the user to perceive information with other senses, e.g., sounds. In future research, the authors of the article aim to attempt to visualize topographic data in a more immersive way, for example by using the VR HMD (Virtual Reality Head-Mounted Display) technology (Halik 2018; Edler et al. 2019a, b). Additionally, in future studies the authors of this article will make an attempt to boost the coverage of the research and to increase the number of 3D objects on the map presented by adding extra elements, such as buildings, trees, etc. In addition, the authors in future 
research intend to present the methodology for objects with a variety of geometries.

Acknowledgements This paper is the result of research on visualization methods carried out within statutory research in the Department of Cartography and Geomatics, Faculty of Geographical and Geological Sciences, Adam Mickiewicz University in Poznań, in Poland.

Open Access This article is licensed under a Creative Commons Attribution 4.0 International License, which permits use, sharing, adaptation, distribution and reproduction in any medium or format, as long as you give appropriate credit to the original author(s) and the source, provide a link to the Creative Commons licence, and indicate if changes were made. The images or other third party material in this article are included in the article's Creative Commons licence, unless indicated otherwise in a credit line to the material. If material is not included in the article's Creative Commons licence and your intended use is not permitted by statutory regulation or exceeds the permitted use, you will need to obtain permission directly from the copyright holder. To view a copy of this licence, visit http://creativecommons.org/licenses/by/4.0/.

\section{References}

Aicardi I, Chiabrando F, Grasso N, Lingua A, Noardo F, Spano A (2016) UAV photogrammetry with oblique images: first analysis on data acquisition and processing. https://www.int-arch-photo gramm-remote-sens-spatial-inf-sci.net/XLI-B1/835/2016/isprs -archives-XLI-B1-835-2016.pdf. Accessed 24 August 2020

Aicardi I, Garbarino M, Lingua A, Lingua E, Marzano R, Piras M (2016) Monitoring post-fire forest recovery using multi-temporal Digital Surface Models generated from different platforms. EARSeL eProc 15(1):1-8. https://doi.org/10.3390/rs6010470

Anai T, Sasaki T, Osaragi K, Yamada M, Otomo F, Otani H (2012) Automatic exterior orientation procedure for low-cost uav photogrammetry using video image tracking technique and Gps information. In: ISPRS-International Archives of the Photogrammetry-Remote Sensing and Spatial Information Sciences, pp 469-474. https://doi.org/10.5194/isprsarchives-XXXIX $-B 7-469-2012$

Arias P, Ordonez C, Lorenzo H, Herraez J (2006) Methods for documenting historical agro-industrial buildings: a comparative study and a simple photogrammetric method. J Cult Heritage 7(4):350354. https://doi.org/10.1016/j.culher.2006.09.002

Barazzetti L, Remondino F, Scaioni M, Brumana R (2010) Fully automatic UAV image-based sensor orientation. https://www.isprs.org/ proceedings/XXXVIII/part1/12/12_02_Paper_75.pdf. Accessed 24 August 2020

Benesha J, Lee J, James DA, White B (2020) Are You for Real? Engineering a Virtual Lab for the Sports Sciences Using Wearables and IoT. Proceedings 49:110. https://doi.org/10.3390/proceeding s2020049110

Bielecka E, Medyńska-Gulij B (2015) Zur Geodateninfrastruktur in Polen. KN-J Cartogr Geogr Inform 65(4):201-208. https://doi. org/10.1007/BF03545142

Clapuyt F, Vanacker V, Van Oost K (2016) Reproducibility of UAVbased earth topography reconstructions based on struc- turefrom-motion algorithms. Geomorphology 260:4-15. https://doi. org/10.1016/j.geomorph.2015.05.011

Clapuyt F, Vanacker V, Schlunegger F, Van Oost K (2017) Unravelling earth flow dynamics with 3-D time series derived from UAV-SfM models. Earth Surface Dynamics 5:791-806. https:// doi.org/10.5194/esurf-5-791-2017
Colomina I, Molina P (2014) Unmanned aerial systems for photogrammetry and remote sensing: a review. ISPRS J Photogram Remote Sens 92:79-97. https://doi.org/10.1016/j.isprsjprs.2014.02.013

Cöltekin A, Oprean D, Wallgrün JO, Klippel A (2019) Where are we now? Re-visiting the Digital Earth through human-centered virtual and augmented reality geovisualization environments. Int J Digit Earth 12(2):119-122. https://doi.org/10.1080/17538 947.2018.1560986

Cybulski P, Wielebski Ł, Medyńska-Gulij B, Lorek D, Horbiński T (2020) Spatial visualization of quantitative landscape changes in an industrial region between 1827 and 1883. Case study Katowice, southern Poland. J Maps 16:77-85. https://doi.org/10.1080/17445 647.2020.1746416

de Kock ME, Gallacher D (2016) From drone data to decisions: Turning images into ecological answers. https://www.innovation arabia.ae/wpcontent/uploads/iarabiadoc/Conference_proceeding s_HEC_2016_2.pdf. Accessed 24 August 2020

Edler D, Keil J, Wiedenlübbert T, Sossna M, Kühne O, Dickmann F (2019) Immersive VR experience of redeveloped post-industrial sites: the Example of "Zeche Holland" in Bochum-Wattenscheid. KN-J Cartogr Geogr Inform 69(4):267-284. https://doi. org/10.1007/s42489-019-00030-2

Edler D, Kühne O, Keil J, Dickmann F (2019) Audiovisual cartography: established and new multimedia approaches to represent soundscapes. KN_J Cartogr Geogr Inform 69(1):5-17. https:// doi.org/10.1007/s42489-019-00004-4

Eugster H, Nebiker S (2008) Uav-based augmented monitoring-realtime georeferencing and integration of video imagery with virtual globes. Archives 37:1229-1236

Gerke M, Przybilla HJ (2016) Accuracy analysis of photogrammetric UAV image blocks: influence of onboard RTK-GNSS and cross flight patterns. https://www.ingentaconnect.com/content/schweiz/ pfg/2016/00002016/00000001/art00002; jsessionid=8ru8515srm qb.x-ic-live-02. Accessed 24 August 2020

Gonçalves JA, Henriques R (2015) UAV photogrammetry for topographic monitoring of coastal areas. ISPRS J Photogram Remote Sens 104:101-111. https://doi.org/10.1016/j.isprsjprs.2015.02.009

Halik $Ł$ (2018) Challenges in converting Polish topographic database of built-up areas into 3D virtual reality geovisualization. Cartogr J 55(4):391-399. https://doi.org/10.1080/00087041.2018.1541204

Halik Ł, Smaczyński M (2018) Geovisualisation of relief in a virtual reality system on the basis of low-level aerial imagery. Pure Appl Geophys 175(9):3209-3221. https://doi.org/10.1007/s0002 4-017-1755-Z

Horbiński T (2019) Progressive evolution of designing internet maps on the example of google maps. Geodesy Cartogr 68(1):177-190. https://doi.org/10.24425/gac.2019.126095

Horbiński T, Medyńska B (2017) Geovisualisation as a process of creating complementary visualisations: static two-dimensional, surface three-dimensional, and interactive. Geodesy Cartogr 66(1):45-58. https://doi.org/10.1515/geocart-2017-0009

Horbiński T, Lorek D (2020) The use of Leaflet and GeoJSON files for creating the interactive web map of the preindustrial state of the natural environment. J Spatial Sci. https://doi.org/10.1080/14498 596.2020 .1713237 (advance online publication)

Kraak M-J, Ormeling F (2010) Cartography: Visualization of Geospatial Data, Person Education Limited, Kraak M.-J., London

Leberl F, Kluckner S, Bischof H (2009) Collection, processing and augmentation of VR Cities. https://phowo.ifp.uni-stuttgart.de/ publications/phowo09/260Leberl.pdf, Accessed 24 August 2020

Lorek D, Medyńska-Gulij B (2019) Scope of information in the legends of topographical maps in the nineteenth century-Urmesstischblätter. Cartogr J. https://doi.org/10.1080/00087041.2018.15474 71 (advance online publication)

Lorek D, Dickmann F, Medyńska-Gulij B, Hannemann N, Cybulski P, Wielebski Ł, Horbiński T (2018) The cultural and landscape 
development of Polish and German industrial centres. Bogucki Wydawnictwo Naukowe, Poznan

MacEachren AM (1994) Visualization in modern cartography: setting the agenda. In: MacEachren AM, Taylor DRF (eds) Visualization in modern cartography. Pergamon Press, London, pp 55-70

Medyńska-Gulij B, Żuchowski TJ (2018) An analysis of drawing techniques used on european topographic maps in the eighteenth century. Cartogr J 55(4):309-325. https://doi.org/10.1080/00087 041.2018 .1558021

Medyńska-Gulij B, Wielebski Ł, Halik Ł, Smaczyński M (2020) Complexity level of people gathering presentation on an animated map-objective effectiveness versus expert opinion. ISPRS Int J Geo-Inf 9(2):117. https://doi.org/10.3390/ijgi9020117

Miřijovský J, Langhammer J (2015) Multitemporal monitoring of the morphodynamics of a mid-mountain stream using UAS photogrammetry. Remote Sens 7:8586-8609. https://doi.org/10.3390/ rs 70708586

Nex F, Remondino F (2014) UAV for 3D mapping applications: a review. Appl Geomat 6(1):1-15. https://doi.org/10.1007/s1251 8-013-0120-x

Nurminen A, Oulasvirta A (2008) Designing interactions for navigation in 3D mobile maps. In: Meng L, Zipf A, Winter S (eds) Mapbased mobile services: design, interaction and usability. Springer, London, pp 198-224

Padró JC, Muñoz FJ, Planas J, Pons X (2019) Comparison of four UAV georeferencing methods for environmentalmonitoring purposes focusing on the combined use with airborne andsatellite remote sensing platforms. Int J Appl Earth Obs Geoinf 75:130-140. https ://doi.org/10.1016/j.jag.2018.10.018

Pérez M, Aguiera F, Carvajal F (2013) Low cost surveying using an unmanned aerial vehicle. https://www.int-arch-photogramm -remote-sens-spatial-inf-sci.net/XL-1-W2/311/2013/. Accessed 24 August 2020

Perez-Martin E, Herrero-Tejedor TR, Gomez-Elvira MA, Rojas-Sola JI, Conejo-Martin MA (2011) Graphic study and geovisualization of the old windmills of La Mancha (Spain). Appl Geogr 31(3):941949. https://doi.org/10.1016/j.apgeog.2011.01.006

Remondino F, Toschi I, Gerke M, Nex F, Holland D, McGill A, Talaya Lopez J, Magarinos A (2016) Oblique aerial imagery from NMA—some best practices. https://www.int-arch-photogramm -remote-sens-spatial-inf-sci.net/XLI-B4/639/2016/. Accessed 24 August 2020

Rossi G, Tanteri L, Tofani V, Vannocci P, Moretti S, Casagli N (2018) Multitemporal UAV surveys for landslide mapping and characterization. Landslides 15:1045-1052. https://doi.org/10.1007/s 1034 6-018-0978-0
Salvini R, Riccucci S, Gullı` D, Giovannini R, Vanneschi C, Francioni M (2014) Geological Application of UAV Photogrammetry and Terrestrial Laser Scanning in Marble Quarrying (Apuan Alps, Italy). https://link.springer.com/chapter/10.1007\%2F978-3-31909048-1_188. Accessed 24 August 2020

Siebert S, Teizer J (2014) Mobile 3D mapping for surveying earthwork projects using an unmanned aerial vehicle (UAV) system. Autom Construct 41:1-14. https://doi.org/10.1016/j.autcon.2014.01.004

Smaczyński M, Medyńska-Gulij B (2017) Low aerial imagery—an assessment of georeferencing errors and the potential for use in environmental inventory. Geodesy Cartogr 66(1):89-104. https:// doi.org/10.1515/geocart-2017-0005

Stanton M, Hartley T, Loizides F, Worrallo A (2017) Dual-Mode User Interfaces for Web Interactive 3D Virtual Environments Using Three.js. https://link.springer.com/chapter/10.1007\%2F978 -3-319-68059-0_47. Accessed 24 August 2020

Uysal M, Toprak AS, Polat N (2015) DEM generation with UAV photogrammetry and accuracy analysis in Sahitler hill. J Int Measure Confed 73:539-543. https://doi.org/10.1016/j.measuremen t.2015.06.010

Virtanen JH, Hyyppä H, Kämäräinen A, Hollström T, Vastaranta M, Hyyppä J (2015) Intelligent open data 3D maps in a collaborative virtual world. ISPRS J Geo-Inform 4(2):837-857. https://doi. org/10.3390/ijgi4020837

Wang J, Garratt M, Lambert A, Wang JJ, Han S, Sinclair D (2008) Integration of $\mathrm{Gps} / \mathrm{Ins} / \mathrm{vision}$ sensors to navigate unmanned aerial vehicles. https://www.isprs.org/proceedings/XXXVII/congress/1_ pdf/166.pdf. Accessed 24 August 2020

Wästfelt A (2020) Ambiguous use of geographical information systems for the rectification of large scale geometric maps. Cartogr J. https://doi.org/10.1080/00087041.2019.1660511 (advance online publication)

Westoby MJ, Brasington J, Glasser NF, Hambrey MJ, Reynolds JM (2012) 'Structure-from-Motion' photogrammetry: a low-cost, effective tool for geoscience applications. Geomorphology 179:300-314. https://doi.org/10.1016/j.geomorph.2012.08.021

Wilson JW (2005) Historical and computational analysis of long-term environmental change: forests in the Shenandoah Valley of Virginia. Hist Geogr 205(33):33-53

Zhang C, Kovacs JM (2012) The application of small unmanned aerial systems for precision agriculture: a review. Precision Agric 13(6):693-712. https://doi.org/10.1007/s11119-012-9274-56 